\title{
La Democracia en América Latina: la alternativa entre populismo y democracia deliberativa
}

\author{
Democracy in Latin America: Between Populism \\ and Deliberative Democracy
}

\author{
OSVALDO GUARIGLIA \\ Consejo Nacional de Investigaciones Científicas y Técnicas, Argentina
}

Resumen. En Política VI 2, $1317 b$ 1-17, Aristóteles define así la democracia: «el rasgo esencial de la democracia es el vivir como se quiere sin ninguna interferencia y de aquí vino el de no ser gobernado, si es posible por nadie, y si no, por turnos. Esta característica contribuye a un sistema general de la libertad fundada en la igualdad». Este modelo normativo dio lugar, históricamente, a dos posibles regímenes políticos, la democracia popular o extrema, basada en la participación directa de todos los ciudadanos, como en Atenas, y una «constitución mixta» que tenía rasgos tanto democráticos como oligárquicos, llamada república en la tradición romana desde Cicerón. La democracia moderna es la heredera de ambos regímenes, moderada por la nueva concepción de los derechos individuales que son propios del pensamiento moderno desde Hugo Grotius hasta la Declaración Universal de los Derechos Humanos. La constitución representativa fue, así, la solución moderna al conflicto entre gobierno de la mayoría y gobierno de las leyes. Desde su Independencia en el siglo XIX, las democracias de América Latina sufren por la tensión no resuelta entre populismo y constitución liberal democrática. El neo-populismo que surgió en los últimos años del siglo xx se presentó como un desafío y una respuesta a las promesas incumplidas de la democracia. Contra los defensores del populismo autoritario, como por ejemplo Ch. Mouffe y E. La-
Abstract. In Politics VI 2, $1317 b$ 1-17, Aristotle defines «democracy» as follows: «the aim of democracy is, ideally, freedom from any interference of government, and, failing that, such freedom as comes from alternation of ruling and being ruled. It contributes, in this way, to a general system of liberty based on equality". Historically, this normative model shaped two possible political regimes, v. gr., popular or extreme democracy, based on direct participation of all citizens, as in Athens, and a «mixed constitution» containing oligarchic as well as democratic features, called «republican» in the roman tradition since Cicero. Modern democracy was the heir of both these Ancient regimes, tempered by the new conception of individual rights belonging to Modern thought from Hugo Grotius to the Universal Declaration of $\mathrm{Hu}-$ man Rights. The representative constitution was, thus, the modern solution to the conflict between government of the majority and government of the laws. Since their Independence in the $19^{\text {th }}$ century, Latin American democracies suffer from the unresolved tension between populism and the liberal constitutional regime. The neo-populism that grew in the last years of $20^{\text {th }}$ century appears as a response and defiance to democracy's unfulfilled promises. Against defenders of authoritarian populism, such as Ch. Mouffe and E. Laclau, I argue that deliberative democracy is a better response to them. 
clau, yo sostengo que la democracia deliberativa es una respuesta superior a esas promesas.

Palabras clave: Democracia, república, derechos individuales, constitución representativa, neo-populismo, América Latina, democracia deliberativa.

Key words: Democracy, republic, individual rights, representative constitution, neo-populism, Latin America, deliberative democracy.

$\S 1$. Al hablar de «democracia», como en el título de este trabajo, debemos procurar distinguir con suficiente precisión los sentidos que estamos atribuyendo a los términos. «Democracia» tiene al menos dos significados diferentes, según se lo use descriptiva o normativamente. Como he señalado en otra parte, ambos usos aparecen ya bien diferenciados en la Política de Aristóteles y se han mantenido desde entonces fundidos en un solo término técnico en la filosofía política (Guariglia, 1996, 201 ss.). En Política VI 2, 1317b 1-17, Aristóteles expone una versión de los principios de todo régimen democrático, dentro de los cuales precisa las siguientes características que constituyen el núcleo normativo del concepto de democracia: «el fundamento del régimen democrático es la libertad — en efecto, suele decirse que sólo en este régimen se participa de libertad- $-[. .$.$] . Una característica de la libertad es el de ser go-$ bernado y gobernar alternativamente, pues el principio de justicia popular consiste en tener igualdad [de derechos] según el número y no según el mérito, y siendo esto lo justo, forzosamente tiene que ser soberana la muchedum$b r e$, y lo que apruebe la mayoría, eso tiene que ser el fin y lo justo. [...] Otra característica es el vivir como se quiere: pues dicen que esto es resultado de la libertad, puesto que lo propio del esclavo es vivir como no se quiere. Este es el segundo rasgo esencial de la democracia, y de aquí vino el de no ser gobernado, si es posible por nadie, y si no, por turnos. Esta característica contribuye a la libertad fundada en la igualdad».

Se encuentran aquí las dos notas distintivas de la concepción tradicional de la democracia, esto es: la igualdad de derechos de todos los ciudadanos (isonomía) y la libertad, entendida como ausencia de esclavitud (eleuthería). De este modo Aristóteles reafirma los principios normativos comunes a todas las democracias, pero indica que hay una gradación en la forma en que cada una de ellas ejercita estos principios, acotando: «la democracia que más parece merecer ese nombre y el pueblo que verdaderamente lo es, son los que se deducen del concepto democrático de la justicia admitido por todos, según el cual la justicia consiste en que todos sean iguales en sentido numérico. En efecto, la igualdad consiste en que no gobiernen en mayor medida los pobres que los ricos, sino que todos sean soberanos por igual de acuerdo al número, pues de esta manera podría juzgarse que efectivamente se dan en el régimen la igualdad y la libertad» (Pol. VI 2, 1318 a 3-10). 
Escojo el modelo normativo que presenta Aristóteles porque, haciendo abstracción de las grandes distancias históricas, nos provee un esquema conceptual que permite utilizar como criterio una doble relación de principio entre los miembros de un mismo régimen para que éste sea considerado «democrático»: la relación de simetría entre sus miembros que implica la igualdad recíproca de derechos (lo que Aristóteles llama «igualdad según el número»), por una parte, y la relación también simétrica de mutuo rechazo que implica que ninguno de los miembros esté sometido a la voluntad ajena, por la otra. De este modelo construido por Aristóteles se derivaron históricamente dos tradiciones, tan pronto confundidas y tan pronto separadas a veces hasta el extremo de enfrentarse entre sí. Me refiero, por supuesto, a los dos regímenes políticos conocidos por los términos democracia y república respectivamente. Sin duda, el mismo Aristóteles contribuye a esta confusión y ambigüedad entre ambos regímenes, al clasificar a la república algunas veces como una especie de la democracia y otras muchas más como una «mezcla de democracia y oligarquía» (Pol. IV 8, 1293b 33-35). Las gradaciones entre ambas dependían por tanto del grado de extensión de la ciudadanía con derechos políticos, es decir, si las restricciones a causa de la propiedad, el origen (nacimiento), etc., eran más o menos estrictas y comprendían a las clases más desprovistas o no (Pol. IV 9, 1294a 30 ss.). Sin embargo, ambos regímenes populares tenían una característica común que usualmente se pasa por alto: se trataba de constituciones en las que todos los que poseían el título de ciudadanos participaban de modo directo de las instituciones y magistraturas del Estado, de modo que las mayorías temporales que se formaban en el ágora ateniense y más tarde en el Campo de Marte romano tomaban decisiones inapelables, que tenían la capacidad de decidir sobre la vida y los bienes de los ciudadanos individuales. Precisamente por esta capacidad de ejercer un poder absoluto, desde Aristóteles hasta Rousseau y Kant, la manera de ejercerlo se convierte en definitoria del régimen: el que usa el poder moderadamente porque presenta un equilibrio mayor entre sus componentes pasará a ser preferentemente designado como republicano, mientras que el que tiende a ejercerlo sin frenos, quedará clasificado como una democracia extrema, en donde el demos o la plebe decide sólo en vista de sus intereses particulares.

Como Rousseau mismo admite, en las naciones modernas ese poder del pueblo soberano frente a sus sujetos, los ciudadanos, se enfrenta a límites estrictos que son los que opone al primero en beneficio de estos últimos el derecho natural (Contr. II, cap. 4). Se trata aquí de la gran innovación, introducida por el jurista holandés Hugo Grocio, que consistió en revertir la perspectiva en la consideración de los derechos. En efecto, mientras que Aristóteles y sus seguidores romanos y renacentistas partían de la concepción del todo, es decir, de la politeía de cada Estado, para definir luego los derechos de los ciudadanos (Pol. VIII 1, 1337 a 26-32, Pocock, 1975, 66 ss.), Grocio, en cambio, invirtió la relación y partió de los derechos propios del individuo que como 
persona cada uno posee desde siempre. Estos derechos son considerados inalienables y se convierten en una «cualidad moral de las personas, facultándolas para tener o hacer algo legalmente» (De iure I, 1, 4, p. 97, citado por Guariglia, 2010, 23). Tenemos así los tres elementos fundamentales que en su combinación definen una constitución moderna: los principios de libertad e igualdad de derechos, la forma de auto-gobierno del pueblo soberano y los derechos innatos de los ciudadanos.

He querido presentar la cuestión desde la perspectiva filosófico-histórica de los regímenes políticos con el fin de esclarecer algunos conceptos básicos que, a mi modo de ver, han sido oscurecidos por una corriente de historia de las ideas y filosofía política en época reciente. Me refiero en especial a aquéllos que han presentado las concepciones de la democracia actual como una oposición entre dos posiciones básicas: por un lado, un liberalismo, escueta y cuidadosamente recortado a un esquema libertario que se limita a sostener un principio de no-interferencia, y, por el otro, un republicanismo, desembarazado de toda su compleja carga histórica y cómodamente simplificado en el principio de no-dominación (cp. Pettit, 2002, 339-356). Lo cierto es, en cambio, que las democracias modernas son igualmente deudoras de las dos tradiciones: la de la soberanía popular, sea bajo la forma de una democracia directa, o sea, bajo la forma de una constitución mixta republicana, por una parte, y la de los derechos subjetivos innatos - para usar la terminología de Kant-, por la otra. Éstos, provenientes del derecho natural de Grocio a Christian Wolf, hicieron su camino hacia el Bill of Rights de la constitución norteamericana y la Declaración de los derechos del hombre y del ciudadano de la constitución francesa, hasta ser incorporados en las diversas constituciones democráticas y ser compendiados, por último, en la Declaración universal de los derechos humanos, proclamada por la Asamblea de las Naciones Unidas en diciembre de 1948 (Lauren, 2003, 16-21). También en las repúblicas hispano-americanas, cuyo bicentenario celebramos el año pasado, la influencia del pensamiento filosófico y político de ambas tradiciones fue manifiesta y decisiva (Chiaramonte, 2000, 33-71).

$\S 2$. Hasta aquí he intentado esclarecer sucintamente la procedencia y la significación de los regímenes políticos involucrados al menos en sus rasgos más específicos. Más allá de esto, la realización histórica de cada uno de ellos dio lugar a una infinidad de matices cuya narración en detalle dejo librada a los historiadores políticos. Me interesa, en cambio, señalar un aspecto importante sobre el que ha puesto fuerte énfasis Q. Skinner como definitorio del régimen republicano defendido por los escritores neo-romanos de Maquiavelo en adelante. Se trata del principio de independencia o no-dependencia ajena de la ciudad o de la nación, que se resume en la sentencia: «un hombre libre sólo puede serlo en una ciudad libre» (Maquiavelo, Discorsi, I, sec. 1-6; Skinner, 1998 [2001], cap. 1, 13 ss.). Es de por sí evidente que una consigna como esa da lugar a distintas interpretaciones según el nivel y el contexto en 
el que se la aplique: por un lado refrenda la soberanía de un determinado cuerpo político frente a todos los otros Estados. Por el otro puede, en cambio, sustentar proclamas dirigidas contra gobiernos jerárquicos en el interior del propio Estado. Así fue utilizada contra la monarquía de Carlos I de Inglaterra por los revolucionarios que finalmente lo destituyeron, o, más adelante, ya en pleno protectorado de O. Cromwell, contra éste y sus generales, representantes de las clases más altas, por parte de los soldados en nombre de las más bajas en el movimiento conocido como los Levellers (Glover, 1999, 46-80). Por fin, ese fue también el caso de los jacobinos franceses, que llevaron bajo la consigna de «libertad, igualdad y fraternidad» al enfrentamiento de las clases más desposeídas contra los grandes propietarios (Domènech, 2004, 80-88). Tenemos así en ambos casos un claro ejemplo de un republicanismo popular que se aleja drásticamente del modelo de equilibrio de la constitución mixta, con su balance interno de los poderes fijados por una constitución, y se inclina fuertemente hacia la democracia extrema antigua, en la que el líder extraía su poder del apoyo incondicional de la masa y debía ejercer sus únicas dotes para satisfacer los incesantes reclamos y para contener al mismo tiempo los irrefrenables apetitos de aquélla (Finley, 1974, 1-25 para Grecia y Brunt, 1974, 74-102 para Roma). Claramente esta especie de republicanismo abjura de la universalidad y previsibilidad que confiere una constitución, precisamente porque la interpretación última de la ley escaparía de la decisión mayoritaria para quedar atrapada en las manos de una elite de jurisconsultos. Nos encontramos sin duda frente a una forma peculiar de auto-gobierno, que solamente puede darse mediante una fuerte confrontación en el interior de la ciudadanía y, de un modo similar al de la democracia extrema antigua, busca la exclusión de una de las partes enfrentadas.

La democracia moderna, como heredera de los dos regímenes populares, la república y la democracia directa, intentó resolver los dilemas que ambos presentan por medio del doble recurso de la representación que permitía incorporar los intereses contrapuestos de la ciudadanía en un cuerpo colegiado reducido, dentro del cual era posible la deliberación y el acuerdo, por un lado, y la elección universal de los representantes y mandatarios por períodos acotados, por el otro. Si, como señala un autor del nuevo republicanismo jurídico norteamericano, la política reside en una forma correcta de deliberación y discusión acerca del bien público, este procedimiento no es posible sino por medio de los principios de la representación: «los mecanismos de responsabilidad prevendrán el hecho de que los representantes defiendan intereses diferentes de aquéllos de sus representados» (Cass Sunstein, citado por Nino, 1997, 144). ¿Pero cómo hacer para que los representantes no antepusiesen sus propios intereses a los del conjunto de los ciudadanos, más allá de estar sujetos a dar cuenta de sus actos ante sus representados? ¿Cómo lograr un criterio claro y preciso para justipreciar que el «bien común» beneficie efectivamente al universo de los ciudadanos por igual? ¿Cómo asegurar, por último, que las decisiones de la mayoría 
respeten los derechos individuales sin que esto limite la voluntad mayoritaria por encima de toda razonabilidad? (véase Michelman, 1986, 40-43). La respuesta de los padres fundadores norteamericanos fue obviamente la adopción de la constitución mixta, la que, según el lema ciceroniano, «siendo módicamente mezclada no irrita por su exigencia el ánimo feroz y salvaje» (De re pub. II 23, 41). La distribución de pesos y contrapesos entre los poderes del ejecutivo, del legislativo y de una justicia independiente harían lo que la razonabilidad de un único soberano, sea éste unipersonal o multitudinario, no podría nunca o muy raramente lograr. Con este paso, comienza en América del Norte la historia moderna de $s u$ democracia, cuya revisión filosófica e histórica desde hace cuatro decenios ha producido una extraordinaria suma de obras de indagación de las ideas y de reflexión sistemática, de las que señalo sólo dos para ilustración de mi aserto: A Theory of Justice de J. Rawls y The Machiavellian Moment de J. Pocock. Dejo ahora de lado esta reconstrucción filosófico-histórica de lo que conocemos como la moderna república democrática de derecho y me concentraré en examinar de aquí en más algunos de los interrogantes que la república representativa ha dejado abiertos para el desarrollo de la democracia como ideal normativo.

Previamente, sin embargo, un breve comentario sobre la situación tan diferente en la que se encontraba la América española cuando se inician las revoluciones emancipadoras. Otro muy distinto era, en efecto, el panorama que se les presentaba a los hombres y mujeres que vivían en las colonias al producirse las revoluciones contra la monarquía española. Como escribía Sarmiento: «[A diferencia de los ciudadanos del norte] Nosotros, al día siguiente de la revolución, debíamos volver los ojos a todas partes buscando con qué llenar el vacío que debían dejar la inquisición destruida, el poder absoluto vencido, la exclusión religiosa ensanchada» (citado por Botana, 1984, 265). El accidentado desarrollo de la historia constitucional posterior muestra que la descripción de Sarmiento se ajustaba a la realidad: mientras que la Constitución de los Estados Unidos fue aprobada, escasamente una década después de su emancipación, las constituciones de las repúblicas latinoamericanas tardaron aproximadamente medio siglo hasta encontrar su forma definitiva (Argentina 1853-62; México 1857, etc.). Pese a ello, sólo muy recientemente y en pocos países es posible considerar que se han tornado una forma de vida normal de las instituciones.

$\S 3$. La historia de la formación de una ciudadanía política en la Argentina durante el siglo XIX hasta comienzos del XX ha sido investigada de un modo esclarecedor por varios historiadores (cp. Halperín Donghi, 1972, 177 ss.; Botana, 1977 y 1984, 2. a parte; Sábato, 1998). El grado de crecimiento en la consciencia política de esa ciudadanía encontró su correlato en el nacimiento, crecimiento y expansión de la opinión pública a través de distintos medios, tanto publicitarios como de participación directa. Como señala la historiadora Sábato, «[p]ara el republicanismo liberal de las dirigencias, el tribu- 
nal de la opinión [pública] se levantaba como la expresión más genuina del interés colectivo de la nación» $(1998,22)$. Tocqueville había ya descubierto que el mismo régimen que hace a los hombres libres e iguales los aísla entre sí y promueve la retracción y el individualismo. Sólo una poderosa tendencia a la comunicación, participación y asociación entre ellos puede contrarrestar en el seno de la sociedad civil esa consecuencia de otro modo inevitable (cp. Tocqueville, DA, II, 2. ${ }^{a}$ Parte, cap. i-v, pp. 463-76). Así surgieron también en Argentina un amplio espectro de asociaciones civiles, sindicales, culturales y políticas que confluyeron en las movilizaciones populares de fines del siglo XIX y principios del XX hasta alcanzar el derecho efectivo al sufragio universal en 1912 y el triunfo de un partido popular, la Unión Cívica Radical, en la elección presidencial de 1916. Pareció, entonces, que la feliz fusión del republicanismo popular y el republicanismo constitucional o liberal, que los Estados Unidos habían alcanzado en 1865, luego de la Guerra Civil, se repetía con el usual retraso de medio siglo en la república federal del sur. Es inútil abundar en lo ya conocido: esa ilusión se desvaneció muy rápidamente en 1930 para dar lugar a otro convulsionado medio siglo de golpes y dictaduras militares, populismos despóticos y nuevos golpes militares hasta la recuperación de la relativa normalidad democrática a fines de 1983. No avanzaré más en esos «tiempos interesantes» en los que me ha tocado vivir gran parte de mi vida, cuya exploración historiográfica seria está aún en estado incipiente (véase L. A. Romero, 2003), sino que voy a concentrarme en el examen de la alternativa que a mi juicio se abre a las repúblicas sudamericanas en el nuevo estadio de la política y la economía global.

Como todos los teóricos políticos coinciden en afirmar, «populismo» es un término sumamente ambiguo que puede referirse a realidades sociales, económicas y políticas bastante diferentes. Donde se lo ha utilizado preferentemente desde la década de los sesenta del siglo pasado en sociología política es en las investigaciones sobre América Latina, a partir de las cuales se ha extendido su uso a otras regiones geográficas, como por ejemplo la Europa oriental postcomunista (Di Tella, 1997, 191-200). Trabajos más recientes han intentado distinguir y clasificar sus significados, tratando de separar las condiciones estructurales y las etapas históricas a las que el término se ha aplicado, por un lado, y su intrínseco núcleo político «intemporal», por el otro (Roberts, 1995; Canovan, 1999, Weyland, 2001, Roberts, 2006). De modo general podemos establecer dos acepciones bien diferenciadas tanto temporal como intrínsecamente: la primera, considerada estructural, que fue elaborada por los estudiosos de la década del sesenta, como Gino Germani, T. Di Tella, etc., y los creadores de la teoría de la dependencia, como F. E. Cardoso y E. Faletto, pone el acento en la existencia de sociedades duales, en las que había por un lado un polo de desarrollo y modernización, y por el otro un país agrario y atrasado. La movilización e incorporación de la nueva masa de emigrantes del interior, casi analfabetos y sin experiencia en las luchas sindicales y políticas, se hizo bajo la 
adhesión de ellos a un movimiento nacionalista con una escasa plataforma teórica, pero fuertemente cohesionado en torno de un líder carismático (Germani, 1968, 289 ss.; 1975, 95 ss.). Por su misma naturaleza, fue considerado un fenómeno de transición que desembocaría, eventualmente, en una democracia representativa normal, una vez que el carisma del líder se haya institucionalizado en un partido político. Un nuevo fenómeno que se alejaba de este «populismo clásico», produjo un cambio brusco del enfoque: la reaparición en la década del noventa del siglo pasado de gobiernos elegidos democráticamente, pero que, apoyándose en mayorías electorales conformadas por coaliciones novedosas no centradas en los partidos políticos tradicionales, obtenían como consecuencia un poder personal poco o nada restringido por un aparato político previo sino surgido más bien de su convocatoria carismática. A diferencia de los anteriores, estos nuevos regímenes no eran necesariamente redistribucionistas y podían ser inclusive neo- conservadores, como los del presidente Menem en Argentina y de Fujimori en Perú (O’Donnell, 1994, 55-69; Roberts, 1995, 82-116). O'Donnell ha denominado a estos nuevos regímenes democracias delegativas y las caracteriza así:

Las democracias delegativas se basan en la premisa de que, quien sea que gane una elección presidencial, tendrá el derecho a gobernar como él (o ella) considere apropiado, restringido sólo por la dura realidad de las relaciones de poder existentes y por un período en funciones limitado constitucionalmente. [...S] u base política debe ser un movimiento [por encima de los partidos que es] la supuestamente vibrante superación del faccionalismo y de los conflictos asociados a los partidos. [...] Los candidatos presidenciales ganadores se sitúan a sí mismos tanto sobre los partidos políticos como sobre los intereses organizados [...] De acuerdo con esta visión, otras instituciones - por ejemplo, los tribunales de justicia y el poder legislativo - constituyen estorbos que acompañan a las ventajas a nivel nacional e internacional de ser un presidente democráticamente elegido (1994, trad. al español, 2009, 12).

Otros autores han preferido mantener la conexión de este nuevo régimen con el populismo clásico, admitiendo sin embargo que se trata de un neo-populismo que puede inclinarse pragmáticamente hacia una política de ajuste neo-conservadora o hacia otra, típicamente clientelar y redistribucionista (Weyland, 2001, 12-16). A fin de poder establecer esa conexión sobre propiedades más estables que las circunstancias más accidentales de carácter social o económico, dichos autores han centrado su definición en el aspecto exclusivamente estratégico de la acción política y del modo de ejercer el poder del líder populista, sucintamente presentados más arriba en la cita de O'Donnell (Weyland, 2001, 13-14). Sin embargo, este aspecto activo de la relación entre gobernantes y gobernados no es suficiente para caracterizar completamente al populismo como régimen político. Es necesario además tomar en consideración los motivos y las expectativas de las masas movilizadas. Como señala 
Canovas, el populismo sacude las estructuras osificadas de la democracia representativa y reaviva los anhelos de participación directa, aunque ilusoria, propios de la democracia antigua o del republicanismo popular (Canovas, 1999, 14 -15). El líder populista despierta estas expectativas presentándose como un salvador que habrá de pulsar sin intermediarios las necesidades y los deseos de los individuos, especialmente de los que se sienten excluidos o rechazados de la corriente central de la democracia institucionalizada. Este aspecto de redención ha estado siempre presente en las dos tradiciones, la democrática extrema y la republicana popular, que heredó, moderándolas, la república representativa. No es, por tanto, sorprendente que las masas motivadas por las expectativas salvíficas, despertadas por el carisma del líder populista, consideren que el poder de ellas y del líder que las representa de modo directo esté por encima, no solamente de los otros poderes, el legislativo y el judicial, sino también por encima de la normativa constitucional e incluso de la internacional, como por ejemplo, las Convenciones que ratificaron la Declaración de los Derechos Humanos civiles y políticos y económicos y sociales (véase sobre Chávez, Correa y Morales, de la Torre, 2009, 25 ss.). Este fervor dinámico que se exhibe como una réplica a la tradición ética y política liberal, es el que los defensores más entusiastas del populismo como un sistema político bipolar permanente subrayan de modo enfático (Mouffe, 2000, 13-17; Laclau, 2005, 150-161, 199 ss.).

$\S 4$. Retornemos por un momento a los principios normativos que sintetizaban las líneas conductoras de la democracia representativa, heredadas de sus predecesoras antiguas: la relación de simetría entre sus miembros que implica la igualdad recíproca de derechos (lo que Aristóteles llamaba la «igualdad según el número»), por una parte, y la relación también simétrica de mutuo rechazo que implica que ninguno de los miembros esté sometido a la voluntad ajena, por la otra. Kant sintetizaba estas dos relaciones al señalar que determinan «la independencia, que consiste en no ser obligado por otros sino a aquello a lo que también recíprocamente podemos obligarlos; por consiguiente, la cualidad del hombre de ser su propio señor» (RL, Ak 237-8). Si volvemos la mirada sobre las condiciones reales en las que han vivido los ciudadanos de casi toda América Latina durante el segundo centenario, deberemos admitir que estamos muy lejos de haber dado muchos pasos en dirección a ese ideal. Más bien encontramos unas sociedades que, salvo admirables excepciones, como Costa Rica y Uruguay, se han deslizado hacia una desigualdad en muchos casos extrema. Desigualdad implica sujeción, pérdida relativa de la independencia, carencia de capacidades y de oportunidades, ausencia de fines $\mathrm{y}$, por último, anihilamiento de la propia autonomía. El corto siglo $\mathrm{xx}$ no ha pasado sin dejar profundas huellas. Hoy somos conscientes de que un régimen no se define como democrático por la mera repetición de comicios más o menos manipulados a intervalos más o menos regulares que permiten un cambio más o menos pacífico de autoridades. La democracia es un régi- 
men exigente que no puede sostenerse sin el apoyo superpuesto de la totalidad de los ciudadanos, y éste no puede ser forzado, sea por coacción o por engaño. Aquéllos que han sido privados de su autonomía, viven excluidos de los derechos que debería asegurarles una democracia, tanto en lo que concierne a sus derechos subjetivos como a sus derechos políticos. En esas condiciones, como en el famoso argumento de Pascal en favor de apostar por la fe en la existencia de Dios, no es extraño que el profeta populista despierte una fe ciega en sus multitudinarios adherentes con la misma incitación: «iApostad, total, ¿qué tenéis que perder?!». *

No es aventurado, por tanto, afirmar que el populismo arranca de las propias promesas frustradas de la democracia, especialmente cuando ésta es reducida a una simple agregación de intereses privados sujeta a la regla de la mayoría. En efecto, aunque esta concepción podría ser admitida en el caso de las democracias más desarrolladas que han disfrutado los beneficios de un generoso estado de bienestar, como algunas del hemisferio norte - y aún así con grandes reservas (cp. Cohen, 1991, 221-25; 1997, 411-21) - , es directamente inaceptable como una concepción de la democracia para países que han sufrido y sufren de una profunda desigualdad entre sus ciudadanos. Como afirmé más arriba, es erróneo dar por supuesta la posesión entre los peor situados de una capacidad para gozar plenamente de su autonomía y estar en condiciones de planear razonablemente sus vidas. Más bien, como la existencia del populismo lo pone de manifiesto, precisamente es la carencia de la posibilidad de desarrollar la propia autonomía en amplias franjas de la población la que fuerza a éstas a agruparse en asociaciones espontáneas para salir de su aislamiento y hacer valer sus demandas. El fenómeno de los «piqueteros» que desde la crisis de 2001 en Argentina ha proliferado, en parte espontáneamente y en parte con apoyo explícito de los gobiernos de los presidentes Néstor y Cristina Kirchner, es un claro ejemplo de ello. Como señala acertadamente de la Torre,

«[e]l populismo representa simultáneamente la regeneración de los ideales participativos y de igualdad de la democracia así como la posibilidad de negar la pluralidad de lo social sin la cual el ideal democrático puede degenerar en formas autocráticas y plebiscitarias de aclamación a un líder construido como la encarnación del pueblo y de la nación» (2009, 31-32).

La democracia deliberativa parte justamente de las deficiencias de las que adolece la democracia representativa, en especial en aquellas sociedades en las que se ha abierto una sima infranqueable entre los mejor y los peor situados, pero pone su meta en una dirección completamente opuesta al populis-

* El ex presidente Carlos Menem ganó las elecciones de 1989 con el siguiente lema como toda plataforma política «¡Síganme, no los voy a defraudar!». Al comenzar sus discursos él había sustituido el tradicional «compañeros/as» del peronismo clásico por «hermanos y hermanas», como los predicadores mediáticos. 
mo. No exige a cada ciudadano la transferencia de su propia autonomía a una entidad colectiva, la comunidad, el movimiento o el piquete, ni una sujeción de sus convicciones personales o de su libertad de expresión a las directivas que descienden desde el líder y el aparato a la masa. Por el contrario, la democracia deliberativa pretende instaurar unos procedimientos de intercambio reglado entre los ciudadanos sobre la base de razones generales que involucren el interés común de todos los afectados. De esta manera, la democracia deliberativa se coloca a priori por encima del populismo con respecto al criterio normativo de la democracia: la relación simétrica entre ciudadanos libres e iguales. Aún concediendo que el populismo podría promover una mejor distribución de los recursos a favor de los peor situados — una pretensión que contradice empero los datos empíricos (véase Gargarella y Lo Vuolo, 2009)_-, existe un campo de la vida social y política de la democracia en la que esa supuesta superior justicia distributiva no solamente es inexistente sino que se trasforma en su extremo opuesto: la distribución de los derechos y las oportunidades políticas entre los ciudadanos de una sociedad desigual. Este completo fracaso, que el populismo propugna como un necesario medio político, por ejemplo en el ámbito de la democracia sindical, tiene consecuencias inevitables en la profundización de las desigualdades sociales en el interior de la sociedad (cp. Bohman, 1996, especialmente caps. 2 y 3).

Los teóricos que defienden el populismo contra la democracia deliberativa han apelado a una contraposición entre el método dialógico de intercambio de razones en busca de un consenso fundado en la admisión de todos los participantes, por un lado, y la nuda expresión retórica de las pasiones y los afectos como instrumentos perlocucionarios de la persuasión y la diatriba, por el otro. Esta última forma de confrontación a todo o nada, habitual en la arena política latinoamericana, es por cierto más indicada para conducir a un antagonismo de las identidades de los contendientes, que se refuerzan en el calor de la disputa y se cierran a la comprensión de unos y otros, que para convertir a los antagonistas en adversarios que respeten el punto de vista del otro a través del agón político, como afirman sus propulsores (así Mouffe, 2000, 13-17; en contra, Dryzek, 2005, 220-28). Por el contrario, la democracia deliberativa no exige a sus ciudadanos la adhesión incondicionada a doctrinas controvertidas ni a visiones cuasi religiosas de la comunidad cultural, de la naturaleza y de la vida humana, sino que los invita a realizar una razonable suspensión del juicio con respecto a las propias cosmovisiones del mundo a fin de encontrar un espacio común de entendimiento entre todas las convicciones privadas. Esta exigencia está fundada en dos hechos indubitables de las modernas democracias: la existencia de una pluralidad de creencias incompatibles entre sí, por un lado, y la imposibilidad de conciliar todas estas múltiples creencias de ciudadanos considerados libres e iguales sin apelar a medidas de coacción mediante el uso de la fuerza, por el otro. El espacio común que queda abierto para la deliberación 
debe, pues, estrecharse a fin de dar cabida a la participación de todos por igual, lo que implica que el contenido de la razón pública es necesariamente limitado y excluye de sus temas todas aquellas cuestiones que involucren visiones parciales, religiosas, metafísicas o doctrinales de la realidad (Rawls, 1993, 54-66, 212 ss). Con estas limitaciones, es evidente que lo que decanta luego de esta criba metódica son por un lado, los hechos empíricos no controvertidos de la realidad social, económica, cultural, biológica, etc., y por otro las teorías aceptadas sin extendidos cuestionamientos por la comunidad científica especializada, y las normas jurídicas más generales que regulan la comunidad de ciudadanos, comenzando por las leyes constitucionales. Es palmario que todos estos contenidos están permanentemente sometidos a revisión y discusión, pero es también trivial que las reglas de la argumentación que rigen en las distintas disciplinas científicas y en el campo jurídico exigen que, para ser tenidos en cuenta, los cuestionamientos deben ser sustentados por argumentos que integren consistentemente datos empíricos, reglas compartidas de razonamiento, y términos cuyos significados no sean ni engañosos ni sistemáticamente ambiguos.

$\S 5$. No hay duda de que, como señalé más arriba, la democracia es un régimen exigente que no puede sostenerse sin el apoyo superpuesto de la totalidad de los ciudadanos, y éste no puede ser forzado, sea por coacción o por engaño. Esta exigencia intrínseca crea otras exigencias a aquéllos en calidad de partícipes, pues deben estar calificados para comprender, de modo general, los términos en que se plantean los problemas a enfrentar y las propuestas presentadas para resolverlos así como sus fundamentos teóricos. Asimismo, deben estar dispuestos a escuchar todas las demandas de los directa o indirectamente involucrados, a rechazar a quienes no tengan una real base para esas demandas y a elegir la propuesta que satisfaga de la mejor manera posible todos los intereses afectados. Sin duda, ésta es la doble tarea del pueblo soberano en su rol institucional de poder legislativo y en su calidad de fuente originaria de legitimidad política, que se manifiesta a través de la opinión pública razonada (Habermas, 1992, 208 ss., 349 ss.). Esta tarea requiere, a su vez, la capacidad de reflexionar y actuar autónomamente por parte de los ciudadanos $\mathrm{y}$ de parte de las instituciones el esfuerzo permanente y sostenido de capacitar a sus ciudadanos con el doble fin de incorporarse al mercado de trabajo en busca de llevar a cabo sus propios planes de vida y de participar autónomamente en la vida política (Guariglia, 1992, 23-33; 1996, cap. 8; Bohman, 1997, 321 ss.).

Soy consciente de que en las líneas generales de la propuesta que he presentado quedan muchos interrogantes abiertos, tanto con respecto a los géneros de la discusión pública, las formas de comunicación entre representados y representantes, la posible institucionalización de las deliberaciones públicas, entre otros. Comentaré brevemente estas tres cuestiones sólo para mostrar las vías posibles de respuesta. Todos los familiarizados con la retórica saben que 
el argumento en base a tópicos o razones comunes, es decir, lo que técnicamente Aristóteles denominó un entimema, constituye el esqueleto que sostiene el discurso, sin el cual éste se desmorona. Contraponer, entonces, los discursos patéticos a los argumentos en base a razones o carece de sentido o es una falacia. Un discurso puede en apariencia apelar exclusivamente a las emociones más primarias, como el dolor o la ira, pero no por eso carecer de razones, probablemente basadas en un interés particular que por cálculo se pretende ocultar. Con respecto a las formas de comunicación entre los representantes y sus ciudadanos, las diferencias entre los países del Norte con instituciones más arraigadas y los del Sur son más bien de grado que de especie, ya que las dificultades que se presentan son muy similares, agravadas en el segundo caso por la dificultad de una parte de la población para acceder a los medios públicos. Hay, por cierto, una condición necesaria, que es en general mucho más respetada en las democracias arraigadas que en las delegativas: la existencia de canales públicos independientes que permiten un acceso directo a los debates parlamentarios, y una política de medios sin control directo del gobierno, por supuesto con la excepción inexplicable de Italia. Por el contrario, como ha sido ya señalado por la crítica académica, los gobiernos neopopulistas se han inclinado hacia un autoritarismo creciente, para el que toda crítica de los medios no debe ser tolerada sino en lo posible ahogada en su mismo origen (De la Torre, 2009, 30-33; O'Donnell, 2010). Esto nos lleva al último punto, el de la institucionalización, para la cual han comenzado a ponerse en práctica diferentes fórmulas (véase Crocker, 2008, passim). Aquí hay, nuevamente, una condición necesaria que el neopopulismo intenta soslayar por todos los medios, usualmente con éxito en la medida en que conserve las mayorías de representantes adictas: la presencia y permanencia de un debate parlamentario sin constricciones y accesible, al menos en sus episodios más importantes, al gran público. En efecto, solamente respetando esta institución básica de toda república democrática, es posible extender luego la participación y el diálogo al público en general a través de la prensa y demás medios y, por último, creando eventos para que se promuevan discusiones en unas comunidades convocadas para fines bien circunscriptos en la que puedan participar todos los involucrados.

En conclusión, si, como han señalado los recientes estudiosos del populismo, éste ha pasado a ser en sus nuevas variantes un régimen no transitorio sino factible de ser instaurado permanentemente en momentos muy difíciles como una forma recortada y deslegitimada de democracia, que se asienta en un republicanismo autoritario de masas, entonces se nos plantea, como filósofos de la política y del derecho, el desafío de examinar otras posibilidades que están también latentes en las estructuras normativas de las dos tradiciones en las que abrevó la moderna democracia. 


\section{BIBLIOGRAFÍA Y REFERENCIAS}

Aristóteles: Pol., Política, edición bilingüe de J. Marías y M. Araujo, Madrid, Instituto de Estudios Políticos, 1970.

Bohman, J. (1996): Public Deliberation: Pluralism, Complexity and Democracy, Cambridge, Mass.-Londres, MIT Press.

Bohman, J. y Rehg, W., editors (1997): Deliberative Democracy: Essays on Reason and Politics, Cambridge, Mass.-Londres, MIT Press.

Bohman, J. y Richardson, H. (2009): «Liberalism, Deliberative Democracy, and "Reasons that All Can Accept"», Journal of Political Philosophy, 17, 253-274.

BotAnA, N. (1977): El orden conservador: la política argentina entre 1880 y 1916, Buenos Aires, Sudamericana.

Botana, N. (1984): La tradición republicana, Buenos Aires, Sudamericana.

Botana, N. (2010, editor): Argentina 2010: entre la frustración y la esperanza. Buenos Aires, Taurus.

Brunt, P. A. (1974): «The Roman Mob», en M. I. Finley editor, Studies in Ancient Society, London-Boston, Routledge \& Kegan Paul, 74-102.

Canovan, M. (1999): «Trust the People! Populism and the Two Faces of Democracy», Political Studies, 47, 2-16.

Chiaramonte, J. C. (2000): «Fundamentos iusnaturalistas de los movimientos de independencia», Boletín del Instituto de Historia Argentina y Americana «Dr. Emilio Ravignani», 3. ${ }^{\text {a }}$ serie, 22, 33-71.

Cicerón, M. T. (1979): De re pub., De re publica, texto latino y trad. alem. K. Ziegler, Darmstadt, Wissensch. Buchgesell.

Cohen, J. (1991): Review of R. Dahl, Democracy and Its Critics, Journal of Politics, $53,221-25$.

Cohen, J. (1997): «Procedure and Substance in Deliberative Democracy», en BOHMAN y REHG, 407-437.

Crocker, D. (2008): Ethics of Global Development: Agency, Capability, and Deliberative Democracy, Cambridge, Cambridge U.P.

DE LA TorRe, C. (2009): «Populismo radical y democracia en los Andes», Journal of Democracy en Español, I, 24-37, accesible en: http://www.journalofdemocracyenespanol.cl/pdf/delatorre.pdf, volumen 1, julio.

De SAnctis, G. (1912): Atthis, Storia della repubblica Ateniese, 2. ${ }^{\text {e }}$ ed., Torino, Fratelli Bocca.

Di Tella, T. (1997): «Populism into the Twenty-first Century», Government and Opposition, 32, 187-200.

DOMÈNECH, A. (2004): El eclipse de la fraternidad: una revisión republicana de la tradición socialista, Barcelona, Crítica.

DRYZEK, J. (2005): «Deliberative Democracy in Divided Societies. (Alternatives to Agonism and Analgesia)», Political Theory, 33, 218-242.

FAtovic, C. (2005): «The Anti-Catolic Roots of Liberal and Republican Conception of Freedom in English Political Thought», Journal of the History of Ideas, 66, 37-58. 
Finley, M. I. (1974): «Athenian Demagogues», en M. I. Finley editor, Studies in Ancient Society, London-Boston, Routledge \& Kegan Paul, 1-25.

Flower, H. ed. (2004): Cambridge Companion to the Roman Republic, New York, Cambridge UP.

Freeman, S. (2000): «Deliberative Democracy: A Sympathetic Comment», Philosophy \& Public Affairs, 29, 371-418.

Freeman, S. (2007): Justice and the Social Contract: Essays on Rawlsian Political Philosophy, New York, Oxford U.P.

Gargarella, R. y Lo Vuolo, R. (2009): «Peligros del estatismo para pocos», en Clarín 23-12-2009.

Germani, G. (1968): Política y sociedad en una época de transición, Buenos Aires, Paidós.

Germani, G. (1975): Autoritarismo, fascismo e classi sociali, Bolonia, Il Mulino.

Glover, S. D. (1999): «The Putney Debates: Popular versus Élitist Republicanism», Past \& Present 164, 47-80.

GuARiglia, O. (1992): «El concepto normativo de "persona” y los requisitos mínimos de justicia distributiva en una sociedad democrática», Desarrollo Económico 32, 23-33.

GuARIgLiA, O. (1996): Moralidad: Ética universalista y sujeto moral, Buenos Aires, Fondo de Cultura Económica.

GuARIGLIA, O. (2002): Una ética para el siglo XXI. (Ética y derechos humanos en un tiempo posmetafísico), Buenos Aires, Fondo de Cultura Económica.

Guariglia, O. (2010a): En camino de una justicia global, Barcelona-Madrid, Marcial Pons.

Guariglia, O. (2010b): «La República y la ética: una relación conflictiva», en BOTANA, editor, págs. 183-215.

GuARIGLIA, O. (2011): «Democracia: origen, concepto y evolución según Aristóteles», Doxa (Cuadernos de Filosofía del derecho), 34, en prensa.

Halperín Donghi, T. (1972): Revolución y guerra, Buenos Aires, Siglo XXI.

HABERMAS, J. (1992): Faktizität und Geltung: Beiträge zur Diskurstheorie des Rechts und des demokratischen Rechstaats, Francfort, Suhrkamp.

Habermas, J. (1997): Die Einbeziehung des Anderen: Studien zur politischen Theorie. Francfort, Suhrkamp.

KANT, Immanuel (1968): RL, Die Metaphysik der Sitten: I, Rechtslehre, Kants Werke, Akademie Textausgabe, Berlin, W. De Gruyter, vol. VI, pp. 203-372, Ak; [trad. cast. A. Cortina y J. Conill, Madrid, 1989].

Lauren, P. G. (2003): The Evolution of International Human Rights, 2. ${ }^{\text {a }}$ ed., Filadelfia, U. Pennsylvania Press.

LACLAU, E. (2005): La razón populista, Buenos Aires, Fondo de Cultura Económica.

Machiavelli, N. (1969): Discorsi, Discorsi sobre la prima deca di Tito Livio, en Opere politiche, a cura di M. Puppo, Firenze, Le Monnier.

Michelman, F. (1986): «Foreword: Traces of Self-Government», Harvard Law Review, 100, 4-77. 
Mouffe, Ch. (2000): «Deliberative Democracy or Agonistic Pluralism», Institute of Advanced Studies, Vienna, Political Science Series, accessible en: http://space. ihs.ac.at/newpage/-IHS-Departments-2/Political-Science-1/Publications-18/Political-Science-Series2/Publications-19/publication-page:5.htm.

Nino, C. S. (1997): La constitución de la democracia deliberative, Barcelona, Gedisa.

O’Donnell, G. (1994): «Delegative Democracy», Journal of Democracy 5, 55-69; traducción española, «Democracia Delegativa», Journal of Democracy en Español, I, 2009, 7-23, accessible en: http://www.journalofdemocracyenespanol.cl/pdf/ odonnell.pdf, volumen I, julio 2009.

O’Donnell, G. (2010): «El riesgo de un deslizamiento de la democracia al autoritarismo», Clarín, 12-01-2010.

PAtTen, A. (1996): «The Republican Critique to Liberalism», British Journal of Political Science, 26, 25-44.

PetTit, Ph. (1997): Republicanism: A Theory of Freedom and Government, Oxford, Clarendon Press.

Pettit, Ph. (2002): «Keeping Republican Freedom Simple», Political Theory, 30, 339-356.

Pocock, J. (1975): The Machiavellian Moment: Florentine Political Thought and the Atlantic Republican Tradition, Princeton-Londres-Princeton U.P.

Pocock, J. (1981): «Virtues, Rights, and Manners», Political Theory, 9, 353-368.

Rawls, J. (1993): Political Liberalism, New York, Columbia U.P.

Rawls, J. (1999): «The Idea of Public Reason Revisited», en The Law of Peoples, Cambridge Mass.-Londres, Harvard U.P., 131-180.

RoBerts, K. (1995): «Neoliberalism and the Transformation of Populism in Latin America», World Politics, 48, 82-116.

Roberts, K. (2006): «Populism, Political Conflict, and Grass-Roots Organization in Latin America», Comparative Politics, 38, 127-148.

Rodgers, D. (1992): «Republicanism: the Career of a Concept», Journal of American History, 79, 11-38.

Romero, L. A. (2003): La crisis argentina: una mirada al siglo XX, Buenos Aires, Siglo XXI.

Rousseau, J. J. (1962): Contr., Du contrat social ou Principes du droit politique, Paris, Garnier Frères.

SÁBATO, H. (1998): La política en las calles: entre el voto y la movilización, Buenos Aires, Sudamericana.

SKINNER, Q. (1998): Liberty before Liberalism, trad. italiana, Torino, Einaudi, 2001.

Tocqueville, A. DE (1996): DA, La democracia en América, trad. esp., México, Fondo de Cultura Económica.

Weyland, K. (2001): «Clarifying a Contested Concept: Populism in the Study of Latin American Politics», Comparative Politics, 34, 1-22. 